\title{
Synthesis and Aminolysis of $N, N$-Diethyl Carbamic Ester of HOBt Derivatives
}

\author{
Sherine Nabil Khattab, Seham Yassin Hassan, Ezzat Awad Hamed, Fernando Albericio, ${ }^{\dagger, \star,}, * *$ and Ayman El-Faham* \\ Department of Chemistry, Faculty of Science, University of Alexandria, Alexandria 21321, Egypt \\ *E-mail: Aymanel_faham@hotmail.com \\ ${ }^{\dagger}$ Institute for Research in Biomedicine, Barcelona Science Park, University of Barcelona, 08028 Barcelona, Spain \\ ${ }^{\ddagger}$ Department of Organic Chemistry, University of Barcelona, 08028 Barcelona, Spain \\ *E-mail: E-mail:albericio@irbbarcelona.org \\ ${ }^{\S}$ CIBER-BBN, Networking Centre on Bioengineering Biomaterials and Nanomedicine, Barcelona Science Park, \\ University of Barcelona, 08028-Barcelona, Spain \\ Received June 5, 2009, Accepted October 11, 2009
}

\begin{abstract}
The reaction of $N, N$-diethyl carbamates of $1 H$-[1,2,3]triazolo[4,5-b]pyridin-1-ol (4-HOAt) 7, 3H-[1,2,3]triazolo[4,5$b]$ pyridin-3-ol (7-HOAt) 8, $1 \mathrm{H}$-benzo[ $d][1,2,3]$ triazol-1-ol (HOBt) 9, 6-chloro-1H-benzo[ $d][1,2,3]$ triazol-1-ol (ClHOBt ) 10, 6-(trifluoromethyl)-1H-benzo[ $d][1,2,3]$ triazol-1-ol $\left(\mathrm{CF}_{3}-\mathrm{HOBt}\right) \mathbf{1 1}$, and 6-nitro- $1 H$-benzo[ $[d][1,2,3]$ triazol1-ol $\left(\mathrm{NO}_{2}-\mathrm{HOBt}\right) 12$ with morpholine and piperidine in $\mathrm{CH}_{3} \mathrm{CN}$ underwent acyl nucleophilic substitution to give the corresponding carboxamide derivatives. The reactants and products were identified by elemental analysis, IR and NMR. We measured the kinetics of these reactions spectrophotometrically in $\mathrm{CH}_{3} \mathrm{CN}$ at a range of temperatures. The rates of morpholinolysis and piperidinolysis were found to fit the Hammett equation and correlated with $\sigma$-Hammett values. The values were 1.44 - 1.21 for morpholinolysis and $1.95-1.72$ for piperidinolysis depending on the temperature. The Brønsted-type plot was linear with a $\beta_{\mathrm{lg}}=-0.49 \pm 0.02$ and $-0.67 \pm 0.03$. The kinetic data and structure-reactivity relationships indicate that the reaction of $\mathbf{9 - 1 2}$ with amines proceeds by a concerted mechanism. The deviation from linearity of the correlation $\Delta \mathrm{H}^{\#} v s . \Delta \mathrm{S}^{\#}$ and plot of $\log \mathrm{k}_{\text {pip }} v s . \log \mathrm{k}_{\text {morph }}$ and Brønsted-type correlation indicate that the reactions of amines with carbamates $\mathbf{7}$ and $\mathbf{8}$ is attributed to the electronic nature of their leaving groups.
\end{abstract}

Key Words: $N, N$-diethyl carbamic esters, 1-Hydroxybezotriazole, Aminolysis, Acylation/Nucleophilic substitution, Linear free energy relationship

\section{Introduction}

It has been proposed that acyl-transfer reactions for carbamates with nucleophiles proceed via either a concerted, a stepwise or a substitution via elimination-addition mechanism, depending on the nature of the nucleophile, the substrate, its leaving group and the solvents involved. ${ }^{1-14}$ Carbamates are characterized by the lone pair of electrons on $\mathrm{N}$, which can delocalize into the $\pi^{*}$ orbital of the carbonyl group by an $\eta \mathrm{N} \rightarrow \pi^{*}$ $\mathrm{C}=\mathrm{O}$ interaction (similar to that reported for $\eta \mathrm{N} \rightarrow \pi^{*} \mathrm{C}=\mathrm{S}$ interaction). ${ }^{15}$ This facilitates the formation of a tetrahedral structure, which can be a transition state in the concerted mechanism or an intermediate in the stepwise one. ${ }^{15}$ Scheme 1 shows the possible pathway mechanisms of acyl-transfer reactions of carbamates with amines.

Shawali et al. ${ }^{13}$ proposed a stepwise mechanism with ratelimiting breakdown of a tetrahedral intermediate $T^{ \pm}$for the reaction of carbamate with amine. The stepwise mechanism (a) could involve two reaction pathways, an overall second-order, $\mathrm{k}_{2}$, (uncatalyzed reaction), and an overall third-order, $\mathrm{k}_{3}$, (the reaction is catalyzed by the amine). Alternatively, pathway (b) proceeds through a concerted mechanism involving transition state $\mathrm{T}^{ \pm}$concerted. The last pathway (c), which is possible only when $\mathrm{R}_{2}=\mathrm{H}$, takes place only in non-polar solvents to give the isocyanate intermediate. ${ }^{14,16}$

The linear free-energy relationship (LFER) is one of the most popular probes to determine reaction mechanisms. This relation- ship informs about the type of electronic effect responsible for acyl-transfer and whether a polar or a charge transfer effect is involved. The sign of reaction constant $\rho$ is invariably positive for stepwise and E1CB mechanism. ${ }^{17}$ When the $\rho$ values are larger than 2, the reaction proceeds by E1CB or by a stepwise mechanism in which the acyl-transfer reactions $\mathrm{B}_{\mathrm{AC}}{ }^{2}$ are most likely to occur by rate-limiting expulsion of leaving group anion from $\mathrm{T}^{ \pm}(\rho \approx 6.24-4.78)^{18}$ i.e. rate-limiting breakdown of a tetrahedral intermediate $\mathrm{T}^{ \pm}$. When $\rho$ is positive and smaller than $2(\rho<2)$, the reaction is characteristic of $\mathrm{a} \mathrm{BC}_{\mathrm{AC}}^{2}$ mechanism. It proceeds by a stepwise mechanism in which the rate-limiting step is the formation of the tetrahedral intermediate. ${ }^{19}$ However,

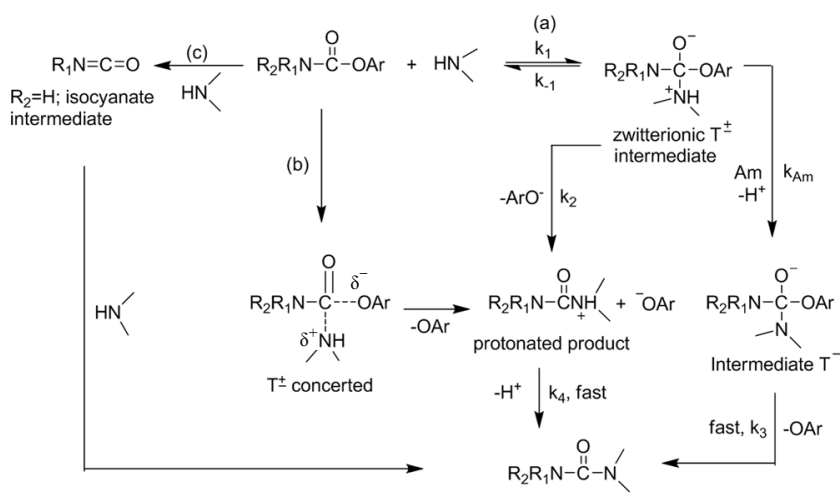

Scheme 1 
the simultaneous bond breakage and bond formation of the carbonyl carbon in $\mathrm{T}^{ \pm}$concerted, Scheme 1, pathway (b) breaks only slightly (if at all) in the transition state. ${ }^{20}$ Since the effects of substituent more or less cancel, small $\rho$ values for concerted mechanisms were reported. ${ }^{18}$ Based on the poor Hammett correlation, it has been reported that acyl-transfer reactions proceed through an addition intermediate in the rate-determining step. ${ }^{17,21}$

To extend our kinetic research on the aminolysis of heterocycle carbamates, ${ }^{22}$ here we studied the mechanism of the reaction of secondary alicyclic amines, such as morpholine and piperidine, with $N, N$-diethyl carbamic acid ester derivatives 712. The main goal of this study was to evaluate the effect of leaving groups and the basicity of the amines (morpholine and piperidine) on the kinetics and mechanism of aminolysis. The sign and magnitude of reaction constant $\rho^{23,24}$ and the Brønsted coefficient of the leaving group $\beta_{\mathrm{lg}}{ }^{25,26}$ were used as mechanistic criteria to gain insight into the concerted or stepwise nature of the process.

\section{Results and Discussion}

The choice of the particular series of heterocycle carbamates 7-12 was based on (i) the fact that analogous activated amino acids are specific substrates for peptide synthesis, ${ }^{27}$ and (ii) the ease of synthesis of these carbamates from commercially available starting materials.

Here we report the synthesis and aminolysis of $N, N$-diethyl carbamates of $1 H$-[1,2,3]triazolo[4,5- $b]$ pyridin-1-ol (4-HOAt) 7, 3H-[1,2,3]triazolo[4,5- $b]$ pyridin-3-ol (7-HOAt) 8, $1 \mathrm{H}$-benzo$[d][1,2,3]$ triazol-1-ol (HOBt) 9, 6-chloro- $1 H$-benzo[d][1,2,3] triazol-1-ol (Cl-HOBt) 10, 6-(trifluoromethyl)-1H-benzo[d] $[1,2,3]$ triazol-1-ol $\left(\mathrm{CF}_{3}-\mathrm{HOBt}\right) \mathbf{1 1}$, and 6-nitro- $1 H$-benzo[ $[d]$ $[1,2,3]$ triazol-1-ol $\left(\mathrm{NO}_{2}-\mathrm{HOBt}\right) \mathbf{1 2}$. The reaction of $N, N$-diethyl carbamates 7-12 with morpholine and piperidine in $\mathrm{CH}_{3} \mathrm{CN}$
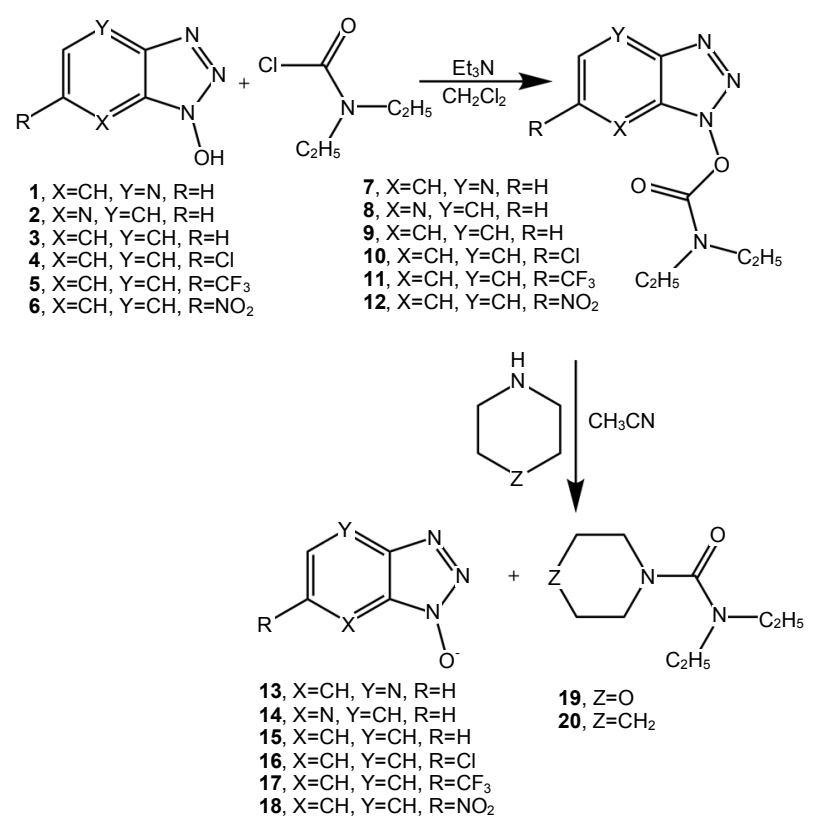

Scheme 2 gave the corresponding substitution products, $N, N$-diethylmorpholine-4-carboxamide 19 and $N, N$-diethylpiperidine-4-carboxamide 20 respectively (Scheme 2).

The active esters 7-12 were readily prepared by reaction of $\mathrm{N}, \mathrm{N}$-diethyl carbamoyl chloride with 4-HOAt (1), 7-HOAt (2), $\mathrm{HOBt}(\mathbf{3}), \mathrm{Cl}-\mathrm{HOBt}(4), \mathrm{CF}_{3}-\mathrm{HOBt}(\mathbf{5})$, and $\mathrm{NO}_{2}-\mathrm{HOBt}(\mathbf{6})$ in $\mathrm{CH}_{2} \mathrm{Cl}_{2}$, in the presence of 2 eq. of triethylamine (TEA) at $0{ }^{\circ} \mathrm{C}$, which was further stirred for $3 \mathrm{~h}$ at room temperature (Scheme 2). Elemental analysis, IR and NMR spectroscopy confirmed the structure of compounds 7-12.

The IR spectrum of $7,{ }^{22} \mathbf{8},{ }^{22},,^{22} \mathbf{1 0}, \mathbf{1 1}$, and $\mathbf{1 2}$ in $\mathrm{KBr}$ showed sharp peaks at wave numbers $1775,1781,1770,1774,1777$, and $1779 \mathrm{~cm}^{-1}$ respectively, corresponding to the $\mathrm{C}=\mathrm{O}$ group. The ${ }^{1} \mathrm{H}$ NMR spectrum of 7-12 in $\mathrm{CDCl}_{3}$ showed two triplet peaks in the range $\delta 1.20-1.27$ and $1.36-1.43 \mathrm{ppm}$, and two quartet peaks in the range $\delta 3.39-3.44$ and $3.56-3.62$ ppm. The relatively shielded protons of one $\mathrm{N}$-ethyl group are presumably because they are located in the cone field (anisotropic effect) of the carbonyl group. ${ }^{22}$ The NMR spectra of compounds 7-9 were discussed briefly in our previous study. ${ }^{22}$ Compounds 10-12 showed three peaks corresponding to their three aromatic protons. The singlet proton corresponding to $\mathrm{H}-7$ for compounds 10-12 resonated at $\delta 7.46,7.79$, and 8.44 ppm respectively. The peak at 8.44 ppm of compound 12 appeared as a doublet with coupling constant $1.5 \mathrm{~Hz}$, corresponding to ${ }^{4} J$ coupling of $\mathrm{H}-7$ proton with $\mathrm{H}-5$. The doublet peaks at $\delta 7.32,7.61$, and $8.17 \mathrm{ppm}$ were analogous to $\mathrm{H}-4$ proton for compounds 10, 11 and 12 respectively. The higher deshielded protons of compounds $\mathbf{1 0}$, 11 and $\mathbf{1 2}$ corresponding to the $\mathrm{H}-5$ protons resonated at 7.93, 8.15 , and 8.27 ppm respectively. As expected, the H-5 peak at $8.27 \mathrm{ppm}$ showed a doublet of doublet multiplicity due to its long range coupling with the $\mathrm{H}-7$ proton $\left({ }^{4} J=1.5 \mathrm{~Hz}\right)$. The ${ }^{13} \mathrm{C}$ nmr spectra of 10-12 showed eleven resolved carbon signals. Four in the sp3-carbon region, six in the aromatic carbon region and the carbonyl signal at $\delta 151.47,151.40$, and $151.19 \mathrm{ppm}$ respectively. On the basis of a previous IR and NMR study, ${ }^{22}$ we established the active esters 7-12 to be in the O- rather than the $\mathrm{N}$-form.

The reaction of the aryl carbamate derivatives (7-12) with morpholine or piperidine in $\mathrm{CH}_{3} \mathrm{CN}$ afforded 19 or $\mathbf{2 0}$. These products were also directly synthesized by the reaction of $N, N$ diethyl carbamoyl chloride with morpholine or piperidine in $\mathrm{CH}_{2} \mathrm{Cl}_{2}$.

The IR and NMR spectra of compound 19 were discussed briefly in our previous work. ${ }^{22}$ The IR spectrum of $\mathbf{2 0}$ in $\mathrm{KBr}$ showed a sharp peak at $1646 \mathrm{~cm}^{-1}$, corresponding to the $\mathrm{C}=\mathrm{O}$ group. The ${ }^{1} \mathrm{H}$ NMR spectrum of $\mathbf{2 0}$ in $\mathrm{CDCl}_{3}$ showed one triplet peak at $\delta 1.05 \mathrm{ppm}$, corresponding to the two $\mathrm{CH}_{3}$ groups, one singlet peak at $\delta 1.51 \mathrm{ppm}$, corresponding to the three $-\mathrm{CH}_{2}$ groups of the piperidine moiety, one multiplet peak range at $\delta$ $3.09-3.14 \mathrm{ppm}$, corresponding to the two $\mathrm{N}-\mathrm{CH}_{2}$ groups of piperidine moiety, and two $\mathrm{CH}_{2}$ groups of the $\mathrm{N}, \mathrm{N}$-diethyl moiety.

The reaction of $N, N$-diethyl carbamates 7-12 with morpholine and piperidine in $\mathrm{CH}_{3} \mathrm{CN}$ at a range of temperatures $\left(30-45^{\circ} \mathrm{C}\right)$ obey a clean second-order rate law, Eq. (1) and Eq. (2), where [Subs] and [Morph] or [Pip] are the concentrations of $N, N$-diethyl carbamate ester (7-12) and morpholine or piperidine, respectively. 
Table 1. Specific rate constants ${ }^{a}$ and activation parameters for the reactions of 7-12 with morpholine in $\mathrm{CH}_{3} \mathrm{CN}$

\begin{tabular}{|c|c|c|c|c|c|c|}
\hline \multirow{2}{*}{ Cpd. } & \multicolumn{4}{|c|}{$K_{2}\left(1 \mathrm{~mol}^{-1} \mathrm{~s}^{-1}\right) \times 10^{4}$} & \multirow{2}{*}{$\Delta H^{\#}\left(\mathrm{Kcal} \mathrm{mol}^{-1}\right)$} & \multirow{2}{*}{$-\Delta S^{\# \mathrm{~b}}$ (e.u.) } \\
\hline & $30{ }^{\circ} \mathrm{C}$ & $35^{\circ} \mathrm{C}$ & $40{ }^{\circ} \mathrm{C}$ & $45^{\circ} \mathrm{C}$ & & \\
\hline 7 & $13.79 \pm 0.07$ & $15.58 \pm 0.01$ & $18.44 \pm 0.01$ & $22.52 \pm 0.02$ & $5.57 \pm 0.60$ & $38.06 \pm 3.30$ \\
\hline 8 & $3.74 \pm 0.04$ & $4.95 \pm 0.05$ & $5.36 \pm 0.05$ & $6.74 \pm 0.06$ & $6.41 \pm 0.90$ & $53.06 \pm 2.90$ \\
\hline 9 & $2.26 \pm 0.02$ & $2.92 \pm 0.03$ & $3.41 \pm 0.06$ & $4.92 \pm 0.06$ & $8.40 \pm 1.10$ & $47.58 \pm 3.40$ \\
\hline 10 & $7.04 \pm 0.01$ & $8.61 \pm 0.07$ & $10.22 \pm 0.11$ & $11.77 \pm 0.11$ & $5.95 \pm 0.30$ & $53.26 \pm 2.41$ \\
\hline 11 & $10.02 \pm 0.14$ & $12.06 \pm 0.19$ & $13.45 \pm 0.16$ & $16.82 \pm 0.04$ & $5.75 \pm 0.59$ & $53.24 \pm 4.94$ \\
\hline 12 & $23.32 \pm 0.12$ & $27.29 \pm 0.14$ & $32.37 \pm 0.27$ & $35.43 \pm 0.48$ & $4.85 \pm 0.44$ & $54.52 \pm 4.29$ \\
\hline$\rho^{b}$ & $1.44 \pm 0.07$ & $1.37 \pm 0.06$ & $1.37 \pm 0.04$ & $1.21 \pm 0.09$ & & \\
\hline
\end{tabular}

${ }^{a} k_{2}=k_{\text {obs }} /$ [morpholine]. Rate constants were calculated by the least-squares method and the correlation coefficient was 0.99 in most cases. ${ }^{b} \rho$ values are estimated from the plot of $\log \mathrm{k}_{2} v s$. $\sigma$ Hammett values for the reaction of morpholine with carbamates 9-12. The correlation coefficient was 0.99 in most cases.

Table 2. Specific rate constants ${ }^{a}$ and activation parameters for the reactions of 7-12 with piperidine in $\mathrm{CH}_{3} \mathrm{CN}$

\begin{tabular}{|c|c|c|c|c|c|c|}
\hline \multirow{2}{*}{ Cpd. } & \multicolumn{4}{|c|}{$K_{2}\left(1 \mathrm{~mol}^{-1} \mathrm{~s}^{-1}\right) \times 10^{4}$} & \multirow{2}{*}{$\Delta H^{\#}\left(\mathrm{Kcal} \mathrm{mol}^{-1}\right)$} & \multirow{2}{*}{$-\Delta S^{\# \mathrm{~b}}$ (e.u.) } \\
\hline & $30{ }^{\circ} \mathrm{C}$ & $35^{\circ} \mathrm{C}$ & $40^{\circ} \mathrm{C}$ & $45^{\circ} \mathrm{C}$ & & \\
\hline 7 & $89.29 \pm 1.16$ & $95.15 \pm 1.56$ & $104.97 \pm 0.85$ & $117.37 \pm 3.89$ & $2.90 \pm 0.33$ & $58.31 \pm 5.52$ \\
\hline 8 & $15.30 \pm 0.11$ & $19.72 \pm 0.16$ & $22.57 \pm 0.10$ & $27.76 \pm 0.26$ & $6.75 \pm 0.55$ & $49.09 \pm 3.41$ \\
\hline 9 & $7.15 \pm 0.08$ & $9.34 \pm 0.11$ & $12.22 \pm 0.12$ & $17.48 \pm 0.10$ & $10.67 \pm 0.70$ & $37.73 \pm 2.37$ \\
\hline 10 & $33.92 \pm 0.36$ & $45.63 \pm 0.45$ & $61.71 \pm 0.62$ & $75.74 \pm 0.96$ & $9.78 \pm 0.53$ & $37.51 \pm 1.90$ \\
\hline 11 & $71.10 \pm 0.53$ & $96.82 \pm 1.00$ & $115.03 \pm 1.45$ & $147.56 \pm 1.04$ & $8.44 \pm 0.64$ & $40.47 \pm 2.84$ \\
\hline 12 & $161.68 \pm 1.84$ & $194.42 \pm 3.28$ & $242.13 \pm 2.16$ & $269.45 \pm 4.42$ & $6.10 \pm 0.57$ & $46.55 \pm 3.93$ \\
\hline$\rho^{b}$ & $1.95 \pm 0.23$ & $1.90 \pm 0.26$ & $1.87 \pm 0.22$ & $1.72 \pm 0.24$ & & \\
\hline
\end{tabular}

${ }^{a} k_{2}=k_{\text {obs }} /\left[\right.$ pip] . Rate constants were calculated by the least-squares method and the correlation coefficient was 0.99 in most cases. ${ }^{b} \rho$ values are estimated from the plot of $\log \mathrm{k}_{2} v s . \sigma$ Hammett values for the reaction of piperidine with carbamates 9-12. The correlation coefficient was 0.99 in most cases.

$$
\begin{aligned}
& \text { Rate }=\mathrm{k}_{\Psi}[\mathrm{Sub}] \\
& \left.\mathrm{k}_{\Psi}=\mathrm{k}_{2} \text { [Amine }\right] \\
& \text { Amine }=\text { Morph or Pip }
\end{aligned}
$$

The second-order rate constants, $\mathrm{k}_{2}$, summarized in Table 1 , were obtained from a straight line plot of $\mathrm{k}_{\Psi} v s$. four to five [Mor$\mathrm{ph}$ ] and [Pip], where $\mathrm{k}_{\Psi}$ is the pseudo-first-order rate constant. The reactions were measured spectrophotometrically by monitoring the formation of 4-OAt ${ }^{-22} 7-\mathrm{OAt}^{-22} \mathrm{OBt}^{-22}, 6-\mathrm{Cl}-\mathrm{OBt}^{-}$, 6- $\mathrm{CF}_{3}-\mathrm{OBt}^{-}$and 6- $\mathrm{NO}_{2}-\mathrm{OBt}^{-}$anions 13-18 (see Exp.). Similar values of $\mathrm{k}_{2}$ were obtained by dividing $\mathrm{k}_{\Psi}$ by the corresponding morpholine or piperidine concentration. This finding indicates that the titled reactions were not catalyzed by the amine.

As expected, the rates were faster for the amine that showed stronger amine nucleophilicity (piperidine) and for the substrate with greatest electron-withdrawing group in the leaving group, thereby indicating that the reaction is a typical nucleophilic substitution, Scheme 1 pathways (a) and (b). As for carbamates 712, the rate constant for morpholinolysis was 3-8 fold smaller than that of the piperidinolysis reaction, as shown in Tables 1 and 2 , as the second-order rate constant $\mathrm{k}_{\mathrm{Am}}$ increases with increasing amine basicity. We propose that the piperidinolysis and morpholinolysis of carbamates $\mathbf{9 - 1 2}$ proceed through the same mechanism, as indicated from the linear plot of $\log \mathrm{k}_{\text {pip }}$ vs. $\log \mathrm{k}_{\text {morph }}$ at all the temperatures studied (gradient at $30^{\circ} \mathrm{C}$ $1.24 \pm 0.26,98 \%$ ) (Figure 2). In contrast, these plots, including carbamates $\mathbf{7}$ and $\mathbf{8}$, showed a deviation of these substrates from linearity. This finding could be due to differences in electronic contribution of the triazolopyridine moiety vs. the benzotriazolo one or to a different mechanism. ${ }^{22}$

The aminolysis of heterocycle carbamates 7-12 can proceed by the three mechanisms discussed above (Scheme 1), depending on the basicity of the amine, the nature of the leaving group, the solvent used, and the classification of the $\mathrm{N}$ atom of the nonleaving group. ${ }^{1-15}$ The mechanism based on the formation of the isocyanate was ruled out because carbamates 7-12 do not have hydrogen atoms, which are required for the elimination. The

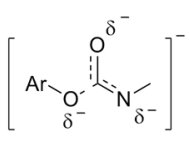

$1 \mathrm{a}$

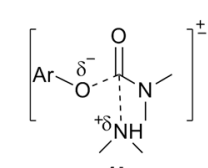

$1 b$

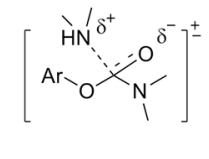

1c

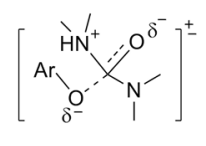

$1 d$
Figure 1. Transition states of the aminolysis of heterocycle carbamates 7-12 could proceed by (a) E1CB mechanism (b) $\mathrm{B}_{\mathrm{AC}}{ }^{2}$ mechanism: concerted process $\mathrm{T}^{ \pm}$concerted (c) stepwise mechanism with rate-determining formation of tetrahedral intermediate (d) stepwise mechanism with rate determining expulsion of the leaving group. 
$\mathrm{B}_{\mathrm{AC}}{ }^{2}$ mechanism can proceed by a concerted mechanism (Scheme 1, pathway b) or stepwise mechanism in which the ratedetermining step is the formation of a tetrahedral intermediate or amine catalysis or the expulsion of the leaving group (Scheme 1, pathway a) in the rate-determining step. The possibility of the reaction to proceed by amine catalysis was rejected on the grounds that the reaction is second-order. Figure 1 shows the transitions states corresponding to the three plausible mechanisms.

Structure-reactivity relationships have provided useful information to study the reaction mechanism, namely the Hammett correlation. The reactivity differences among the carbamates 712 were ascribed only to the electronic effect of the R-substituents, since the steric effect of the substituent can be ruled out. This is because the R-substituents are placed too far away from the carbonyl carbon to provide a significant shielding effect. The rate of reaction was increased by the presence of electronwithdrawing substituents as well as the electron-withdrawing effect of the aza atom in the fused aromatic ring of the leaving group moiety.

The electronic effect of the substituents in the leaving group moiety can be quantified by the use of a Hammett equation (3), in which $\mathrm{k}$ is the rate constant for the reaction of the substrate series with a given substituent, $\mathrm{k}_{0}$, is the rate constant for the reaction of the parent compound 9 , with $\mathrm{R}=\mathrm{H}, \sigma$ is the substituent constant and $\rho$ is the reaction constant.

$$
\log \mathrm{k}=\rho \sigma+\log \mathrm{k}_{0}
$$

The value of $\rho$ is a measure of the susceptibility of the rate constant for a given mechanism of a given reaction type to the influence of substituents. ${ }^{23,24}$ Reactions with positive $\rho$ values are aided by electron withdrawal from the aromatic ring and vice versa for reactions with negative $\rho$ values.

Tables 1 and 2 reveal that rate data of 9-12 with substitution at the meta-like position fitted the Hammett equation. ${ }^{28}$ Accordingly, we propose that inductive effects of the R-substituents account for the reactivity of the carbamates 9-12 towards morpholinolysis. To facilitate the interpretation of the rate data, the Hammett polar substituent parameter $\sigma$ of the R-substituent may be useful. In addition, piperidinolysis of carbamates 9-12 was found to fit the Hammett equation i.e. reactivity was governed by polar effects in a fashion similar to morpholinolysis.

Furthermore, $\rho$ values were 1.44 - 1.21 for morpholinolysis and 1.95-1.72 for piperidinolysis (Table 1,2). The greater $\rho$ values for piperidinolysis compared to that for morpholinolysis indicate that carbamates 9-12 are relatively more susceptible to the latter process. This is because of the higher basicity of piperidine $\left(\mathrm{p} k_{\mathrm{a}}=18.8\right)$ than morpholine $\left(\mathrm{p} k_{\mathrm{a}}=16.0\right)$ in MeCN. ${ }^{29 \mathrm{a}}$ The increased basicity of amines is responsible for their enhanced reactivity in $\mathrm{MeCN}{ }^{29 b}$ This observation indicates that morpholinolysis, like piperidinolysis, proceeds by a mechanism in which the development of the leaving group anion is well advanced in the transition state, i.e. the increase in the positive $\rho$ values are attributed to the greater bond cleavage in the expulsion of the leaving groups from the transition state $\mathrm{T}^{ \pm}$. This concept of mechanism is in agreement with the $\rho$ values reported in the literature for the reaction with an $N, N$-disubstituted aryl

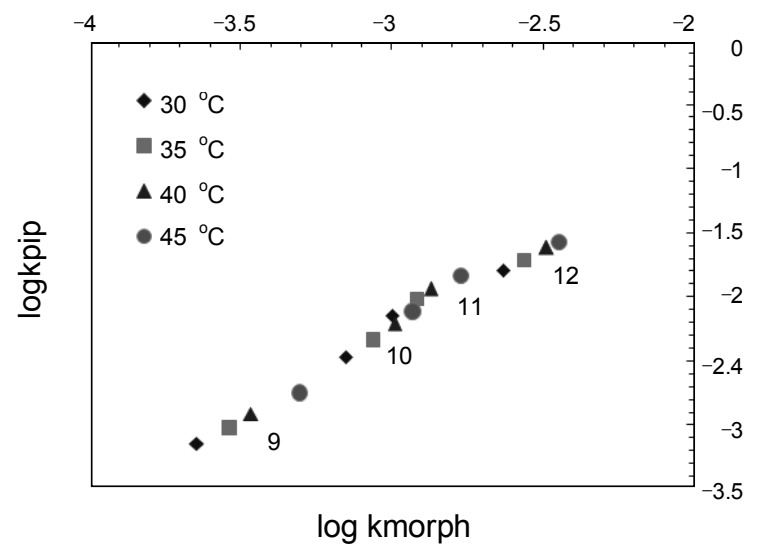

Figure 2. Plot of $\log \mathrm{k}_{\text {pip }}$ against $\log \mathrm{k}_{\mathrm{morph}}$ for carbamates 9-12 at 30 $45^{\circ} \mathrm{C}$

Table 3. $\mathrm{p} K_{\mathrm{a}}$ values of the dissociation constant of compounds 1-6 in $95 \%$ acetonitrile-water at $25{ }^{\circ} \mathrm{C}^{29}$

\begin{tabular}{clr}
\hline No. & Compound & $\mathrm{p} K_{\mathrm{a}}$ \\
\hline 1 & 4-HOAt & 4.086 \\
2 & 7-HOAt & 4.65 \\
3 & $\mathrm{HOBt}$ & 5.65 \\
4 & $6-\mathrm{Cl} \mathrm{HOBt}$ & 4.62 \\
5 & $6-\mathrm{CF}_{3}-\mathrm{HOBt}$ & 4.27 \\
6 & $6-\mathrm{NO}_{2}-\mathrm{HOBt}$ & 3.61 \\
& $\mathrm{~B}_{\text {morpholine }}$ & $-0.49 \pm 0.02$ \\
& $\beta_{\text {piperidine }}$ & $-0.67 \pm 0.03$ \\
\hline
\end{tabular}

carbamates and an aryl ester. ${ }^{21,23,24}$

The Brønsted-type plots for the reaction of carbamates 9-12 with morpholine and piperidine were linear with slopes, $\beta_{\mathrm{lg}}$ $-0.49 \pm 0.02$, and $\beta_{\mathrm{lg}}-0.67 \pm 0.03$ respectively (Figure 3 ). The rate enhancement found with $6-\mathrm{NO}_{2}-\mathrm{HOBt} 12$ relative to 4HOAt 7 relative to 6- $\mathrm{CF}_{3}-\mathrm{HOBt} \mathbf{1 1}$ relative to 6-Cl-HOBt $\mathbf{1 0}$ to 7-HOAt 8 and to HOBt analogs 9 was in harmony with the order of $\mathrm{p} K_{\mathrm{a}}$ values of the liberated leaving groups ${ }^{29}$ (Tables 1 and 2). The $\mathrm{p} K_{\mathrm{a}}$ values of the liberated leaving groups are shown in Table 3. Accordingly, the rate enhancement is consistent with increasing the stability of the leaving group anion liberated.

We suggest that the mechanism for the reactions of compounds 9-13 proceeds via a concerted mechanism. This suggestion is based on the following reasons (i) it is well known that Hammett $\rho$ values increases $c a .2 .4$ times upon solvent change from water to $\mathrm{MeCN}^{31}$ (ii) the $\rho$ values were reported to be 6.07 and 6.24 for the aminolysis of aryl benzoates and acetates respectively in $\mathrm{MeCN}$ which was concluded to proceed through a stepwise mechanism with the departure of the leaving group being the RDS. ${ }^{18}$ While $\rho=3.54$ for piperidinolysis of aryl benzoates in MeCN, was reported to proceed through a concerted mechanism. ${ }^{23 b}$ Thus, the $\rho$ values of $1.44-1.21$ or $1.95-1.72$ for the titled reaction with morpholine and piperidine respectively are too small for a reaction proceeding by two step mechanism and is in agreement with a concerted one. This mechanism concept is reinforced by the Bronsted $\beta_{\lg }$ values of -0.49 and -0.67 


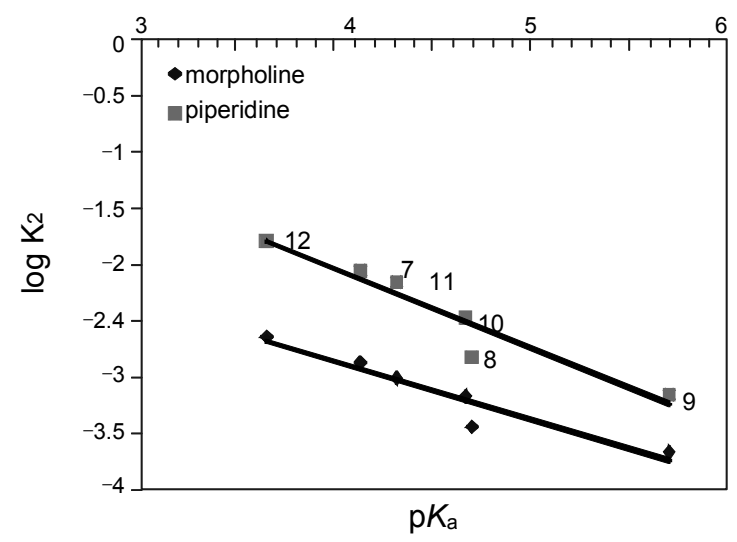

Figure 3. Brønsted-type plots for aminolysis of carbamates 7-12 in $\mathrm{CH}_{3} \mathrm{CN}$ at $30{ }^{\circ} \mathrm{C}$.

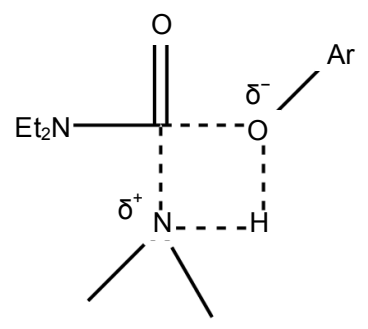

Figure 4. Proposed TS.

for the reaction of compounds 7-12 with piperidine and morpholine respectively, which is also too small for reversible formation of a tetrahedral addition intermediate followed by collapsing of the intermediate, but is typical for reactions, which proceed through a concerted mechanism.

The small $\rho$ values can be explained by the responding to changes in the substituent on the leaving group. Such substituent can alter the partial positive charge on the carbonyl carbon and hence perturb the rate of bond formation between carbon and nucleophile. The effect on the aminolysis rates should be appreciable particularly since the anionic oxygen is poorly solvated in aprotic media. Therefore, the simultaneous bond breakage and bond formation of the carbonyl carbon in Figure 4 accord with the small $\rho$ values for acyl-substituted esters (Tables 1 and 2).

The plots of $\Delta \mathrm{H}^{\#} v s . \Delta \mathrm{S}^{\#}$ values for the reactions of 9-12 with piperidine and morpholine gave straight lines with isokinetic temperatures $186^{\circ} \mathrm{C}$ and $212^{\circ} \mathrm{C}$ respectively (the temperature at which substituent effect is supposed to be reversed). These values were far from the temperatures used in the kinetic runs. Furthermore, the mechanism for the reaction series was common for all members and amines, as indicated by the linearity of the plots of $\log \mathrm{k}_{\text {pip }}$ against $\log \mathrm{k}_{\text {morph }}$ (Figure 2).

The low activation parameters $\Delta \mathrm{S}^{\#}$ and $\Delta \mathrm{H}^{\#}$ (Table 1 and 2) for the reactions of 9-12 with morpholine and piperidine were also in line with the proposed concerted mechanism through the cyclic transition state, Figure $4 .^{32}$

An attempt to correlate $\Delta H^{\#} v s . \Delta S^{\#}$ for the reaction of 7-12 with morpholine and piperidine showed deviation for the 7 and $\mathbf{8}$ isomers. This deviation from linearity, in addition to their deviation in the plot of $\log \mathrm{k}_{\mathrm{pip}} v s . \log \mathrm{k}_{\mathrm{morph}}$ (discussed previ- ously), is presumably due to the difference in the nature of the leaving group. Alternatively, these deviations could be due to differences in electronic contributions of the triazolo-pyridine moiety $v s$. the benzo-triazolo one and not necessarily to a distinct mechanism. This consists with the formation of the cyclic transition state, Figure 4, which is in agreement with that reported earlier, ${ }^{22}$ due to the presence of good leaving groups.

\section{Conclusions}

The aminolysis of heterocycle carbamates 7-12 proceeds either by a concerted mechanism or by a stepwise mechanism, depending on the nature of the leaving group. The neighboring group effect is not relevant in these systems, which gives a clear picture of the reactivity of the different additives in peptide synthesis in terms of racemization and leaving ability. The aminolysis of carbamates 9-12 with amines in acetonitrile proceeds by a concerted mechanism. The proposed mechanism is supported by the low negative $\beta_{\mathrm{lg}}$ value adherence to the RSR, and the low activation parameters. However, the deviation of 7 and 8 from all correlations studied is presumably due to the electronic nature of the leaving group and not to a different mechanism.

\section{Experimental Section}

Materials. The solvents used for kinetic runs were of reagent grade $(\mathrm{BDH})$ and further purifications were carried out. $\mathrm{CH}_{3} \mathrm{CN}$ was used after distillation from anhydrous $\mathrm{K}_{2} \mathrm{CO}_{3}$. Morpholine (99\%) and piperidine (98\%) were used after distillation. Melting points were determined with a Mel-Temp apparatus and are uncorrected. Magnetic resonance spectra $\left({ }^{1} \mathrm{H}\right.$ NMR and ${ }^{13} \mathrm{C}$ NMR spectra) were recorded on a Joel $500 \mathrm{MHz}$ spectrometer with chemical shift values reported in $\delta$ units (part per million) relative to an internal standard. Infrared (IR) data were obtained on a Perkin-Elmer 1600 series Fourier transform instrument as KBr pellets. Ultraviolet (UV) data were recorded on a SHIMADZU (UV-160A) UV-Visible recording spectrophotometer. Elemental analyses were performed on Perkin-Elmer 2400 elemental analyzer, and the values found were within $\pm 0.3 \%$ of the theoretical values. Follow-up of the reactions and checks of the purity of the compounds was doneby TLC on silica gel-protected aluminum sheets (Type 60 GF254, Merck) and the spots were detected by exposure to UV-lamp at $\lambda 254 \mathrm{~nm}$ for a few seconds. The compounds were named using Chem. Draw Ultra version 10, Cambridge soft Corporation.

General procedure for the preparation of $N, N$-diethyl-carbamic acid ester derivatives. $N, N$-Diethyl carbamoyl chloride (10 mmol) was added to a mixture of $\mathrm{HOBt}$ derivatives [1-6], (10 $\mathrm{mmol})$ and $\mathrm{Et}_{3} \mathrm{~N}(2.8 \mathrm{~mL}, 20 \mathrm{mmol})$ at $0{ }^{\circ} \mathrm{C}$ in $\mathrm{CH}_{2} \mathrm{Cl}_{2}(5 \mathrm{~mL})$. Then the reaction mixture was stirred for $3 \mathrm{~h}$ at room temperature. The reaction mixture was diluted with $\mathrm{CH}_{2} \mathrm{Cl}_{2}(80 \mathrm{~mL})$, and the mixture was washed with saturated $\mathrm{NaHCO}_{3}(2 \times 10$ $\mathrm{mL})$, saturated $\mathrm{NaCl}(2 \times 10 \mathrm{~mL})$ and $\mathrm{H}_{2} \mathrm{O}(2 \times 10 \mathrm{~mL})$. The organic layer was dried over anhydrous $\mathrm{Na}_{2} \mathrm{SO}_{4}$ and filtered and the solvent was removed in vacuum. The crude product was purified by column chromatography (EtOAc/hexane, $1: 2$ ) or recrystallized from benzene/petroleum ether. The physical and 
spectra data of the compounds are given below.

6-Chloro-1H-benzo[d] [1,2,3]triazol-1-yl diethylcarbamate (10): Compound 10 was obtained as colorless crystals, $92.2 \%$ yield, 64 - $65^{\circ} \mathrm{C}$. IR ( $\left.\mathrm{KBr}\right): 1774(\mathrm{C}=\mathrm{O}) \mathrm{cm}^{-1} .{ }^{1} \mathrm{HNMR}\left(\mathrm{CDCl}_{3}\right)$ $\delta 1.23,1.37\left(2 \mathrm{t}, 6 \mathrm{H}, 2 \mathrm{CH}_{3}, J=7.7 \mathrm{~Hz}\right), 3.40,3.56$ (2 quart, 4H, $\left.2 \mathrm{CH}_{2}, J=7.7 \mathrm{~Hz}\right), 7.32(\mathrm{~d}, 1 \mathrm{H}, \mathrm{ArH}, J=9.2 \mathrm{~Hz}), 7.46(\mathrm{~s}, 1 \mathrm{H}$, $\mathrm{ArH}), 7.93(\mathrm{~d}, 1 \mathrm{H}, \mathrm{ArH}, J=9.2 \mathrm{~Hz}) .{ }^{13} \mathrm{C} \mathrm{NMR}\left(\mathrm{CDCl}_{3}\right) \delta 13.10$, 14.30, 42.38, 44.05, 108.55, 121.45, 126.08, 129.59, 135.18, 142.05, 151.47. Anal. Calcd. for $\mathrm{C}_{11} \mathrm{H}_{13} \mathrm{ClN}_{4} \mathrm{O}_{2}: \mathrm{C}, 49.17 ; \mathrm{H}$, 4.88 ; N, 20.85. Found: C, 49.18; H, 4.98; N, 21.14.

6-(Trifluoromethyl)-1H-benzo[d] [1,2,3]triazol-1-yl diethylcarbamate (11): Compound 11 was obtained as colorless crystals, $89 \%$ yield, $68-695^{\circ} \mathrm{C}$. IR $(\mathrm{KBr}): 1777(\mathrm{C}=\mathrm{O}) \mathrm{cm}^{-1} .{ }^{1} \mathrm{H}$ $\operatorname{NMR}\left(\mathrm{CDCl}_{3}\right) \delta 1.25,1.41\left(2 \mathrm{t}, 6 \mathrm{H}, 2 \mathrm{CH}_{3}, J=6.9 \mathrm{~Hz}\right), 3.43,3.60$ (2 quart, 4H, $\left.2 \mathrm{CH}_{2}, J=6.9 \mathrm{~Hz}\right), 7.61(\mathrm{~d}, 1 \mathrm{H}, \mathrm{ArH}, J=9.2 \mathrm{~Hz}$ ), $7.79(\mathrm{~s}, 1 \mathrm{H}, \mathrm{ArH}), 8.15(\mathrm{~d}, 1 \mathrm{H}, \mathrm{ArH}, J=8.4 \mathrm{~Hz}) .{ }^{13} \mathrm{C} \mathrm{NMR}$ $\left(\mathrm{CDCl}_{3}\right) \delta 13.07,14.30,42.45,44.13,107.22,107.25,121.51$, 121.63, 128.51, 130.38-131.16 (quart, $\mathrm{CF}_{3}$ ), 144.57, 151.40. Anal. Calcd. for $\mathrm{C}_{12} \mathrm{H}_{13} \mathrm{FN}_{4} \mathrm{O}_{2}$ : C, 47.68; H, 4.34; N, 18.54 . Found: C, 47.47; H, 4.58; N, 18.31 .

6-Nitro-1 $H$-benzo[d] [1,2,3]triazol-1-yl diethylcarbamate (12): Compound 12 was obtained as yellow crystals, $80 \%$ yield, 90 - $91{ }^{\circ} \mathrm{C}$. IR $(\mathrm{KBr}): 1779(\mathrm{C}=\mathrm{O}) \mathrm{cm}^{-1} .{ }^{1} \mathrm{H} \mathrm{NMR}\left(\mathrm{CDCl}_{3}\right) \delta 1.27$, $1.43\left(2 \mathrm{t}, 6 \mathrm{H}, 2 \mathrm{CH}_{3}, J=7.7 \mathrm{~Hz}\right), 3.44,3.62$ (2 quart, $4 \mathrm{H}, 2 \mathrm{CH}_{2}$, $J=7.7 \mathrm{~Hz}), 8.17(\mathrm{~d}, 1 \mathrm{H}, \mathrm{ArH}, J=9.2 \mathrm{~Hz}), 8.27(\mathrm{dd}, 1 \mathrm{H}, \mathrm{ArH}$, $J=9.2 \mathrm{~Hz}, J=1.5 \mathrm{~Hz}), 8.44$ (d, $1 \mathrm{H}, \mathrm{ArH}, J=1.5 \mathrm{~Hz}) .{ }^{13} \mathrm{C} \mathrm{NMR}$ $\left(\mathrm{CDCl}_{3}\right) \delta 13.09,14.34,42.53,44.26,106.38,119.70,121.69$, 128.62, 145.41, 147.63, 151.19. Anal. Calcd. for $\mathrm{C}_{11} \mathrm{H}_{13} \mathrm{~N}_{5} \mathrm{O}_{4}: \mathrm{C}$, 47.31; H, 4.69; N, 25.08. Found: C, 47.46; H, 4.63; N, 24.89.

$\mathrm{N}, \mathrm{N}$-Diethylmorpholine-4-carboxamide (19): ${ }^{22} N, N$-Diethyl carbamoyl chloride $(2.6 \mathrm{~mL}, 20 \mathrm{mmol})$ was added to a solution of morpholine ( $3.5 \mathrm{~mL}, 40 \mathrm{mmol})$ dissolved in $5 \mathrm{~mL} \mathrm{CH}_{2} \mathrm{Cl}_{2}$ at $0{ }^{\circ} \mathrm{C}$. The reaction mixture was stirred for $3 \mathrm{~h}$ at room temperature. The reaction mixture was diluted with $80 \mathrm{~mL} \mathrm{CH}_{2} \mathrm{Cl}_{2}$, then washed with saturated sodium $\mathrm{NaHCO}_{3}(2 \times 10 \mathrm{~mL})$, saturated $\mathrm{NaCl}(2 \times 10 \mathrm{~mL})$ and $\mathrm{H}_{2} \mathrm{O}(2 \times 10 \mathrm{~mL})$. The organic layer was dried over anhydrous $\mathrm{Na}_{2} \mathrm{SO}_{4}$ and filtered and the solvent was removed in vacuum. The crude product was purified by column chromatography (EtOAc/hexane, $1: 2)$ to give a colorless oily product, $85 \%$ yield. IR $(\mathrm{KBr}): 1638(\mathrm{C}=\mathrm{O}) \mathrm{cm}^{-1}$. ${ }^{1} \mathrm{H} \mathrm{NMR}\left(\mathrm{CDCl}_{3}\right) \delta 1.10\left(\mathrm{t}, 6 \mathrm{H}, 2 \mathrm{CH}_{3}, J=6.9 \mathrm{~Hz}\right), 3.19(\mathrm{~m}, 8 \mathrm{H}$, $\left.4 \mathrm{~N}_{-} \mathrm{CH}_{2}\right), 3.67$ (t, $\left.4 \mathrm{H}, 2 \mathrm{O}-\mathrm{CH}_{2}, J=4.6 \mathrm{~Hz}\right)$. Anal. Calcd. for $\mathrm{C}_{9} \mathrm{H}_{18} \mathrm{~N}_{2} \mathrm{O}_{2}: \mathrm{C}, 58.04 ; \mathrm{H}, 9.74 ; \mathrm{N}, 15.04$. Found: $\mathrm{C}, 58.22 ; \mathrm{H}$, $9.89 ; \mathrm{N}, 14.76$.

$\mathbf{N}, \mathbf{N}$-Diethylpiperidine-4-carboxamide (20): $N, N$-Diethyl carbamoyl chloride $(2.6 \mathrm{~mL}, 20 \mathrm{mmol})$ was added to a solution of piperidine ( $3.5 \mathrm{~mL}, 40 \mathrm{mmol}$ ) dissolved in $5 \mathrm{~mL} \mathrm{CH}_{2} \mathrm{Cl}_{2}$ at $0{ }^{\circ} \mathrm{C}$. The reaction mixture was stirred for $3 \mathrm{~h}$ at room temperature. The reaction mixture was diluted with $80 \mathrm{~mL} \mathrm{CH}_{2} \mathrm{Cl}_{2}$, then washed with saturated sodium $\mathrm{NaHCO}_{3}(2 \times 10 \mathrm{~mL})$, saturated $\mathrm{NaCl}$ solution $(2 \times 10 \mathrm{~mL})$ and $\mathrm{H}_{2} \mathrm{O}(2 \times 10 \mathrm{~mL})$. The organic layer was dried over anhydrous $\mathrm{Na}_{2} \mathrm{SO}_{4}$ and filtered and the solvent was removed in vacuum. The crude product was purified by column chromatography (EtOAc/hexane, $1: 2$ ) to give a colorless oily product, $94 \%$ yield. IR $(\mathrm{KBr}): 1646(\mathrm{C}=\mathrm{O}) \mathrm{cm}^{-1}$. ${ }^{1} \mathrm{H} \mathrm{NMR}\left(\mathrm{CDCl}_{3}\right) \delta 1.05\left(\mathrm{t}, 6 \mathrm{H}, 2 \mathrm{CH}_{3}, J=7.7 \mathrm{~Hz}\right), 1.51(\mathrm{~s}, 6 \mathrm{H}$, $\left.3 \mathrm{CH}_{2}\right)$, 3.09-3.14 (m, 8H, $4 \mathrm{CH}_{2}$ ). Anal. Calcd. for $\mathrm{C}_{10} \mathrm{H}_{20} \mathrm{~N}_{2} \mathrm{O}$. $\mathrm{H}_{2} \mathrm{O}: \mathrm{C}, 59.37 ; \mathrm{H}, 10.96 ; \mathrm{N}, 13.85$. Found: C, 59.29; H, 10.90; N, 13.69.
Kinetic measurements. The kinetics of 7-12 with morpholine and piperidine was measured spectrophotometrically using a Shimadzu (UV-160A) spectrophotometer in conjunction with a Shimadzu thermo bath (TB-85). Temperature control $( \pm 0.1$ ${ }^{\circ} \mathrm{C}$ ) was attained by circulating water through cell compartments. The kinetic runs were carried out at four temperatures $\left(30-45^{\circ} \mathrm{C}\right.$ ) in $\mathrm{CH}_{3} \mathrm{CN}$. The rate constants for the reactions of 7-12 with morpholine were measured spectrophotometrically by following the formation of 4-OAt ${ }^{-22} 7-\mathrm{OAt}^{-22}, \mathrm{OBt}^{-22}, 6-\mathrm{Cl}-$ $\mathrm{OBt}^{-}, 6-\mathrm{CF}_{3}-\mathrm{OBt}^{-}$and $6-\mathrm{NO}_{2}-\mathrm{OBt}^{-}$anions 13-18 at $=275,286$, $318,334,362$ and $435 \mathrm{~nm}$ respectively. The rate constants for the reactions of 7-12 with piperidine were measured spectrophotometrically by following the formation of 4-OAt ${ }^{-}, 7-\mathrm{OAt}^{-}$, $\mathrm{OBt}^{-}, 6-\mathrm{Cl}-\mathrm{OBt}^{-}, 6-\mathrm{CF}_{3}-\mathrm{OBt}^{-}$and $6-\mathrm{NO}_{2}-\mathrm{OBt}^{-}$anions 13-18 at $\lambda=362,365,320,334,362$ and $435 \mathrm{~nm}$ respectively. All reactions were carried out under pseudo-first-order conditions, with various concentrations of morpholine $(0.794-1.587 \mathrm{~mol}$ $\left.\mathrm{dm}^{-3}\right)$ or piperidine $\left(0.04-0.95 \mathrm{~mol} \mathrm{dm}^{-3}\right)$ and final concentration of substrates 7-12 $\left(5 \times 10^{-4} \mathrm{~mol} \mathrm{dm}^{-3}\right)$ were used. The pseudofirst-order rate constants $\mathrm{K}_{\Psi}$ were estimated by applying Eq. (4).

$$
\log \left(\mathrm{A}_{\mathrm{t}}-\mathrm{A}_{\infty}\right)=\frac{-k_{\psi} t}{2.303}+\log \left(\mathrm{A}_{0}-\mathrm{A}_{\infty}\right)
$$

Where $A_{0}, A_{t}$ and $A_{\infty}$ are the values of absorbance at zero time, time $t$, and at the end of the reaction, respectively. The $A_{\infty}$ for each run was taken as the experimentally determined values, and $k_{\Psi}$ is the pseudo-first-order rate constant.

\section{References}

1. Jencks, W. P. Catalysis in Chemistry and Enzymology; Mc GrawHill: London, 1969; p 463-553.

2. a) Baxter, N. J.; Rigoreau, L. J. M.; Laws, A. P.; Page, M. I. J. Am. Chem. Soc. 2000, 122, 3375-3385. b) Adalsteinsson, H.; Bruice, T. C. J. Am. Chem. Soc. 1998, 120, 3440-3447.

3. a) Castro, E. A. Chem. Rev. 1999, 99, 3505-3524 b) Castro, E. A.; Cubillos, M.; Santos, J. G.; Tellez, J. J. Org. Chem. 1997, 62, 25122517. c) Castro, E. A.; Cubillos, M.; Santos, J. G. J. Org. Chem. 1996, 61, 3501-3505.

4. a) Um, I. H.; Min, J. S.; Ahn, J. A.; Hahn, H. J. J. Org. Chem. 2000, 65, 5659-5663. b) Um, I. H.; Min, J. S.; Lee, H. W. Can. J. Chem. 1999, 77, 659-666.

5. a) Williams, A. Acc. Chem. Res. 1989, 22, 387-392. b) Ba-Saif, S.; Luthra, A. K.; Williams, A. J. Am. Chem. Soc. 1987, 109, 63626368. c) Bourne, N.; Chrystiuk, E.; Davis, A. M.; Williams, A. J. Am. Chem. Soc. 1988, 110, 1890-1895. d) Deacon, T.; Farra, C. R.; Sikkel, B. J.; Williams, A. J. Am. Chem. Soc. 1978, 100, 25252534.

6. Stefanidis, D.; Cho, S.; Dhe-Paganon, S.; Jencks, W. P. J. Am. Chem. Soc. 1993, 115, 1650-1656.

7. a) Hess, R. A.; Hengge, A. C.; Cleland, W. W. J. Am. Chem. Soc. 1997, 119, 6980-6983. b) Hengge, A. C.; Hess, R. A. J. Am. Chem. Soc. 1994, 116, 11256-11263. c) Hengge, A. C.;Edens, W. A.; Elsing, H. J. Am. Chem. Soc. 1994, 116, 5045-5049.

8. a) Guthrie, J. P. J. Am. Chem. Soc. 1996, 118, 12878. b) Guthrie, J. P. J. Am. Chem. Soc. 1991, 113, 3941-3949.

9. a) Pregel, M. J.; Dunn, E. J.; Buncel, E. J. Am. Chem. Soc. 1991, 113, 3545-3550. b) Buncel, E.; Um, I. H.; Hoz, S. J. Am. Chem. Soc. 1989, 111, 971-975. c) Tarkka, R. M.; Buncel, E. J. Am. Chem. Soc. 1995, 117, 1503-1507. 
10. a) Okuyama, T.; Takano, H. J. Org. Chem. 1994, 59, 472-476. b) Okuyama, T.; Lee, J. P.; Ohnish, K. J. Am. Chem. Soc. 1994, 116, 6480-6481. c) Bender, M. Chem. Rev. 1960, 60, 53-113.

11. a) Um, I. H.; Kim, M. J.; Lee, H. W. Chem. Commun. 2000, $2165-$ 2166. b) Capon, B.; Ghosh, A. K.; Grieve, D. M. A. Acc. Chem. Res. 1981, 14, 306-312. c) Perkins, C. W.; Martin, J. C. J. Am. Chem. Soc. 1985, 107, 3209-3218. d) McClelland, R. A.; Santry, L. J. Acc. Chem. Res. 1983, 16, 394-399.

12. Um, I. H.; Park, Y. M.; Shin, E. H. Bull. Korean Chem. Soc. 1999, 20,392-394.

13. Shawali, A. S.; Harhash, A.; Hassanee, H. M.; Alkaaabi, S. S. J. Org. Chem. 1986, 51, 3498.

14. Menger, F. M.; Glass, L. E. J. Org. Chem. 1974, 39, 2469-2470.

15. Oh, H. K.;. Oh, J. Y. Bull. Korean Chem. Soc. 2006, 27, 143-146.

16. Furuya, Y.; Goto, S.; Itoho, K.; Urasaki, I.; Morita, A. Tetrahedron 1968, 24, 2367-2375.

17. a) Lee, I.; Sung, D. D. Curr. Org. Chem. 2004, 8, 557-567. b) Oh, H. K.; Kim, S. K.; Lee, I. Bull. Korean Chem. Soc. 1999, 20, 10171020. c) Oh, H. K.; Oh, J. Y. Bull. Korean Chem. Soc. 2006, 27, 143-146.

18. Menger, F. M.; Smith J. H. J. Am. Chem. Soc. 1970, 92, 2824-2829.

19. Wentworth, P.; Datta, A.; Smith, S.; Marshall, A.; Partidge, L. J.; Blackburn, G. M. J. Am. Chem. Soc. 1997, 119, 2315-2316.

20. Boucher, G.; Said, B.; Ostler, E. L.; Resmin, M.; Brocklehurst, K.; Gallacher, G. Biochem. J. 2007, 401, 721-726.

21. Um, I. H.; Lee, E.-J.; Jeon, S. E. Bull. Korean Chem. Soc. 2001, $22,1301-1302$.
22. Khattab, Sh. N.; Hassan, S. Y.; Hamed, E. A.; El-Faham, A. J. Chem. Res. 2007, 247-251.

23. a) Um, I. H.; Lee, E.-J.; Fujio, M.; Tsuno, Y. Org. Biomol. Chem. 2006, 4, 2979-2985. b) Um, I. H.; Jeon, S.-E.; Seok, J.-A. Chem. Eur. J. 2006, 12, 1237-1243.

24. a) Jeong, K. S.; Oh, H. K. Bull. Korean Chem. Soc. 2007, 28, 485-488. b) Um, I. H.; Akhtar, K. Bull. Korean Chem. Soc. 2008, 29, 772-776.

25. a) Um, I. H.; Kim, K.-H.; Park, H.-R.; Fujio, M.; Tsuno, Y. J. Org. Chem. 2004, 69, 3937-3942. b) Um, I. H.; Han, H.-J.; Baek, M.-H.; Bae, S.-Y. J. Org. Chem. 2004, 69, 6365-6370. c) Um, I. H.; Lee, E.-J.; Ko, S.-H.; Bae, S.-K. J. Org. Chem. 2006, 71, 5800-5803.

26. a) Um, I. H.; Park, H.-R.; Kim, E.-Y. Bull. Korean Chem. Soc. 2003, 24, 1251-1255. b) Um, I. H.; Park, Y.-M. Bull. Korean Chem. Soc. 2008, 29, 575-579.

27. Albericio, F.; Chinchilla, R.; Dodsworth, D.; Nájera, C. Org. Prep. \& Proc. Int. 2001, 33, 203-303.

28. Johnson, C. D. The Hammett Equation; Cambridge University press: U. V., 1973.

29. a) Spillane W. J.; McGrathm, P.; Brack, C.; O'Byrne, J. Org. Chem. 2001, 66, 6313-6316. b) Um, I. H.; Lee, E. J.; Jeon, S. E. J. Phys. Org. Chem. 2002, 15, 561-565.

30. Fathalla, M. F.; Khattab, Sh. N. unpublished data.

31. Chantooni, M. K., Jr.; Kolthoff, I. M. J. Am. Chem. Soc. 1970, 92 , 7025-7030.

32. Oh, H. K.; Park, J. E.; Sung, D. D.; Lee, I. J. Org. Chem. 2004, 69 , 9285-9288. 